\title{
Research of psychological support of the personality of the senior preschool child and his readiness for school in the conditions of transitive society
}

\author{
Svetlana Bostanova $^{1 *}$, Faizura Semenova ${ }^{2}$, and Dianna Akbaeva ${ }^{1}$ \\ ${ }^{1}$ Aliev Karachai-Cherkess State University, Department of General and Educational \\ Psychology, 369202 Karachaevsk, Russia \\ ${ }^{2}$ Aliev Karachai-Cherkess State University, Faculty of Psychology and Social Work, \\ 369202 Karachaevsk, Russia
}

\begin{abstract}
This article describes the psychological support as a scientific category; analyzes different approaches to the study of psychological support patterns supporting verbal and nonverbal interaction plan affecting the efficiency of psychological support of the individual, highlighted the constructive changes facility wide the influence of psychological support on developing personality. It is proved that in a transitive society psychological support will help the child to adapt to rapidly changing factors of environmental development, to a new type of activity, to new social roles. In practical terms, psychological support can be applied using specific, both individual and group psychological methods with components of modern exercises and psychotechnics. Here the developing subject needs the support of a competent partner in the event community. This article describes the supporting forms, means, methods, techniques that can be used by teachers and educators at the stage of adaptation of first-graders to school.
\end{abstract}

\section{Introduction}

Modern education of a transitive society is a contextual environment of personal development in the period of its formation. This educational space is marked by opportunities and incentives, on the one hand, barriers and specific requirements for its resources - on the other, adaptive abilities, "capable of stimulating the development of human mental potential, acting as a kind of psychological bridge connecting a growing person with universal culture, experience and history" (S. N. Bostanova, F. O. Semenova, 2015) - with the third [1].

"Psychological support is a kind of interpersonal interaction aimed at psychological assistance to the subject, during which there is a positively colored sense of self-confidence, in their abilities. The aim of psychological support is to assist in the development of

\footnotetext{
${ }^{*}$ Corresponding author: bostanova14@,mail.ru
} 
psychological individuality of the subject in the construction of personality formation, the development of the self, in the realization of personal growth during life crises, internal search and selection" (N. G. Derbeneva).

Considering the problem of psychological support, scientists pay attention to the importance of its provision to a mentally healthy person, pointing out that in the construction of psychotherapeutic models, it is necessary to pay attention to the satisfaction of the leading human needs: self-actualization, the self-realization, development of personality, empathy man, self-reliance, good health; adaptation to reality, the ability to control your life under different circumstances (favorable and unfavorable) (A. Maslow, B. Linner of Axelson, I. Thylefors, etc.) [2; 3; 4].

This block of needs has a significant impact on the development of psychological health, a sense of competence, optimization of personal development.

\section{Problem statement}

The significance of the study of the problem of psychological support of the personality of the senior preschooler in the period of adaptation to school in a transitive society is due to the actualization of the study of the processes of socialization and individualization, the deployment of the system of humanization and humanitarization of education, gaining momentum in recent decades.

The construction of a model of psychological support in Russian science is based on the works of scientists L. S. Vygotsky, S. L. Rubinstein, A.V. Petrovsky, V. A. Petrenko, O. S. Gazman, etc.

According to the Russian psychologist A.V. Brushlinsky (1994), the problem under study is particularly relevant in the conditions of "active overcoming of our recent totalitarian, authoritarian, technocratic past" [5]. Such "active overcoming of the past" also affected education at the turn of the XX-XXI centuries, causing the search for new systems, methods, tools aimed at the development of physically and mentally healthy personality and determined the emergence of such a phenomenon as psychological support. We believe that it is mandatory in the work on psychological support of adaptation of older preschoolers to the conditions of the school of modern transitive society will increase the psychological competence of the teacher, who acts as a guide not only developing but also supporting ways.

In the system of providing psychological support to the developing subject, it is important today to include it in the practice of counseling. Based on the tasks and specifics of personal counseling, support can be defined as "energizing empathy", manifested in the fact that the practical psychologist shows his open empathy to the person in such a way that the person accepts it as an approval of his own personality. The most effective methods in the process of counseling are "developing" advice, thanks to which a person reveals the range of likely actions with an incentive search for the best moves and "developing information" that allow a person to act decisively and adequately in the current situation. The most important conditions for providing effective support is to take into account such aspects of personal development in the social context; cultural specificity; psychological readiness to accept help; age characteristics and individual characteristics of the person ( $T$. P. Gavrilova).

\section{Research questions}

The study of psychological support for the personality of the senior preschooler and his adaptation to school in a transitive society raises the question that support as a process of 
purposeful interaction of subjects of educational activity is addressed to a specific person. This problem as the target acts as a consolidation of the internal installations for the success and efficient development, lowering anxiety, providing sustainable self-esteem. In addition, support as a purposeful process will help to develop a positive Self-concept of the younger student, the formation of a trusting attitude to himself as a subject of educational activity and others as translators of interaction in the modern educational environment. It seems that the optimally organized process of psychological support can lead to a normal growth of the personal potential of the future first grader, taking into account the individual psychological characteristics of development and Interpellation for support.

\section{Purpose of research}

As part of the research procedures, we assume that psychological support in the process of adaptation to school in a modern educational environment requires preschoolers with a low level of psychosocial maturity. Also, the effectiveness of psychological support depends on the nature of relationships and self-perception of the child in the family, emotional wellbeing and comfort. These assumptions were tested in an empirical study.

The following methods were used in the study:

- methodology for assessing psychosocial maturity on a test conversation;

- method " Kinesthetic drawing of the family "(R. burns, S. Kaufman);

- talk method.

The study involved 180 first-graders, teachers, parents.

\section{Summary}

As a result of the results we provided the following information. Data on the results of the first method (assessment of psychosocial maturity) showed that a high level of children have received a total of 24-29 points, that is, school-Mature considered 38 children, it is $21.1 \%$. At the average school maturity level, there are 68 children with scores between 20 and 23 . This is $37.7 \%$. Children who have 15 to 19 points have a low level of psychosocial maturity-74 respondents. That is, $41.1 \%$ were relatively unprepared for school life.

The test conversation was necessary to establish contact with the child, to create a trusting relationship during the study. By means of questions of conversation we managed to receive data on the General representations of the child about the world around, about elementary abilities of orientation in usual situations, about a situation in a family.

Thus, out of 180 children, only $21.1 \%$ have a high level of school maturity. These children adequately understand and perceive their age in the present and the future ("now I'm a boy, you grow up - I will uncle," "I'm a girl who will I want to be aunt"). They gave correct answers to the relevant questions. For example, they knew the full name, surname, patronymic of their parents and exactly called the place of their work. These children are positively motivated to study at school, they have a desire to learn and learn. This aspect is a favorable factor in the child's readiness for school, his emotional and social maturity.

$37.7 \%$ of children have an average level of psychosocial maturity. These children want (some of them even dream) to go to school, but not everyone knows about it. On some questions, for example, " Why need in school phone call, Desk, portfolio?", children answered uncertainly, or didn't know concrete, direct purpose of a call and a Desk. Question "What hand do students raise in school when they want to answer?" evoked in children a dual response: uncertainly raising his right hand, the children immediately changed it to the left, and some children on the contrary: changed the left hand to the right, looking in the eyes of the researcher the correct answer. 
Thus, children who have a low level of psychosocial maturity (41.1\%) represent a "risk group". They need psychological support not only in emotional acceptance and approval, but also in broadening their horizons, in processing new life experiences, in stimulating and activating cognitive interest. These future first-graders involuntarily or purposefully "pretend" to special attention, sympathy, assistance from parents and peers, psychologist, teacher.

Data on the nature of relationships and self-perception of the child in the family show that the majority-56.1\% (101) children feel comfortable enough and perceive the relationship in the family as emotionally close and supportive. At the same time, the interpretation of the drawings showed that $17.2 \%$ (31) of children obviously experience serious difficulties in the family (indicative features of their drawing are the absence of all family members, drawings consisting of clearly limited groups, separation of family members by means of walls; eviction of themselves or one of the family members, etc.).

The most striking in this regard are the drawings of children, which instead of family members painted "I and friend" or "I and the animal" and "enemy - I - friend". It is interesting to note that the drawings of boys are more aggressive with a pronounced tendency to protest against the existing type of relations in themselves, which is obviously due to the difference in attitude and the tactics of family education of boys and girls.

The presence of emotional problems in the family showed $27.2 \%$ (49) of respondents, among which are typical: a sense of isolation; disconnection of family members; emotional problems in relations with his father, brothers and sisters; a sense of uncertainty in their importance to the family; aggression; lack of emotional warmth.

The study also found that $26.1 \%$ (47) of children rated family relationships as not "warm enough"; $32.2 \%$ (58) did not experience enough emotional support at school and $18.3 \%$ (33) rated their mood and emotional well-being as not good enough. This leads to the conclusion that a certain part of the children, which in our case made up a third of the studied contingent, experience emotional problems, which can be a significant obstacle in the successful adaptation to school. This group of first graders requires increased emotional and family support; a thorough, in-depth analysis of the causes of emotional difficulties and the organization of individual psychological support from adults.

Having studied the possibilities of psychological support at the stage of adaptation to school in a transitive society and adapting the program (trainings, exercises, games) of psychological support for first-graders in the interactive space "child-adult", we received the following results of the study.

Of 180 children, $52.1 \%$ have a high level of school maturity and $47.8 \%$ have an average level of psychosocial maturity. The positive dynamics was the results of the method "Kinesthetic drawing of the family": the nature of comfortable relationships and selfperception of the child in the family is shown in $75.4 \%$ of children.

As a result of approbation of the program of psychological support it is stated: growth of adaptive opportunities of the younger school student; increase of trust to the adult as a source of psychological support; increase of competence of teachers and parents as a condition of rendering effective support.

\section{Conclusion}

Analysis of psychological research in the field of psychological support has revealed the main methods and methods of its implementation. Among them are highlighted:

- psychodiagnostics to identify the difficulties of determining the potential in the application of self-knowledge for self-development in a transitive society; 
- psychological education, which increases the level of personal psychological competence, increases the effectiveness of the interaction of the developing personality in different planes "I-others", "I-myself", "I-the leading activity", " I-the world»;

- psychological and psychoprophylactic counseling, which not only develops a strategy and tactics to solve the problem, but also expands the idea of possible ways of self-support;

- psychological training, which accumulates experience in the use of supportive interaction in the optimization of their own development;

- methods and techniques of adaptive behavior are worked out, there is a training in constructive ways of adaptation;

- psychological correction implies correction and positive transformation of the developing subject in intellectual, emotional, value-semantic, motivational and behavioral terms in order to optimize development.

The main mechanisms of psychological support are: understanding, recognition, advance, trust, praise, empathy, reflection.

Generalization of the results of our analysis allows us to identify the position of psychological support, studied earlier:

1. focusing on the strengths of the child and the payment of deficiencies;

2. supporting and stimulating the child's faith in their development;

3. the possibility of removing the feelings of psychological discomfort in a situation of failure; the use of personal development strategies, interaction, advances, implementation of psychological protection, pre-emptive strategy evaluation $[1 ; 6$; 7].

Summarizing the analyzed material, it can be concluded that psychological support today is understood as a certain system of scientifically based methods and techniques that contribute to adaptation to the conditions of implementation of the leading activity. Implementation of psychological support is due to the optimization of the psychological state of the developing person due to the full resolution or reduction of the relevance of psychological problems that prevent adaptation and self-realization at each stage of life.

Despite the Declaration of the need to develop a system of psychological support in the modern school, according to N. Krylova, the theory and practice of support is still "virgin" field of national psychology. This is evidenced by the trivial misunderstanding of teachers, teachers of pedagogical universities, managers, middle-level officials of the deep meanings that the technology of pedagogical and psychological support carries in solving the problems of reforming education, deepening its humanistic content and individualization of methods [8].

Thus, it can be concluded that, on the one hand, modern psychological science has accumulated sufficient material of theoretical and applied nature, allowing to develop effective programs of psychological support for the development of the child's personality in the process of adaptation to the educational environment, on the other - in practice there is a shortage of variable programs of this type. In this regard, a deep scientific study of conceptual support programs and their instrumental support is relevant and relevant modern educational practice.

\section{References}

1. S.N. Bostanova, F.O. Semenova, Scientific notes of the University named after P. F. Lesgaft. 10, 230-236 (2015)

2. V.P. Bardakhanova, Class teacher. 3, 9-50 (2000)

3. F.B. Berezin, Psychological and psychophysiological adaptation of man (Nauka, Leningrad, 1988)

4. D. Myers, Social psychology (Piter, St. Petersburg, 2017) 
5. A.V. Brushlinsky, Problems of psychology of the subject (Institute of Psychology RAS, Moscow, 1994)

6. N.N. Mikhailova, S.M. Yusfin, Class teacher. 3, 81-87 (2000)

7. K. Rogers, Counseling and psychotherapy (EKSMO-Press, Moscow, 1999)

8. N.B. Krylova, Class teacher. 3, 92-103 (2000) 